\author{
Aging and Oxidative Stress \\ Guest Editor: Mitsuyoshi Matsuo
}

\title{
Aging and the Accumulation of Oxidative Damage to DNA
}

\author{
Takao Kaneko* \\ Redox Regulation Research Group, Tokyo Metropolitan Institute of Gerontology, 35-2 Sakaecho, Itabashi-ku, \\ Tokyo 173-0015, Japan
}

Received 1 September, 2003; Accepted 14 October, 2003

\begin{abstract}
Summary The oxidative stress hypothesis of aging is currently one of the most popular explanations for the cause of aging. Oxidative stress, including that due to reactive oxygen species, causes lesions to biomolecules such as DNA, protein and lipids. 8-Oxo-2'-deoxyguanosine (8-oxodG) is a major oxidative product of DNA and can be detected using a variety of assay methods. For an accurate measurement of 8-oxodG, it is important to minimize as much as possible the oxidation of intact DNA during its isolation from cells or tissues and during the hydrolysis of DNA to nucleosides. The most popular analytical technique is high-performance liquid chromatography with electrochemical detection. The levels of oxidative damage to DNA are likely to increase in mammalian tissues during aging, although it is not clear whether the levels increase linearly during aging or exponentially in aged animals. The accumulation of oxidative damage to DNA is recognized as inducing mutations and dysfunction during aging. The steady state levels of oxidative damage to DNA are proposed to depend on the balance between the formation and repair of damage. The repair activity appears to be weak in aged animals compared with young animals, but antioxidative activity has not been shown to undergo a consistent changing pattern. Thus, it is assumed that the decline in repair activity in aged animals leads to the accumulation of oxidative damage in aged tissues.
\end{abstract}

Key Words: aging, oxidative stress, DNA damage, 8-oxo-2'-deoxyguanosine

\section{Introduction}

During the aging process, the functional capacities of a variety of physiological systems undergo progressive impairment after the maturational phase, decaying the ability to maintain homeostasis and resulting in death. Many hypotheses have been offered to explain the mechanism of the aging pro-

\footnotetext{
* To whom correspondence should be addressed.

Tel: +81-3-3964-3241 Fax: +81-3-3579-4776

E-mail: kaneko@tmig.or.jp
}

cess. The oxidative stress hypothesis of aging, which was first proposed as the free radical hypothesis of aging [1], is currently one of the most popular explanations for the cause of aging. In this hypothesis, the progressive and irreversible accumulation of molecular oxidative damage, induced by oxidative stress, is a main causal factor underlying the age-related losses of physiological functions. This hypothesis has been widely accepted because numerous studies have shown a correlation between increasing in age and the accumulation of oxidative damage to cellular biomolecules $[2,3]$. Since not only free radicals but also non-radical species attack biomolecules oxidatively, 
"reactive oxygen species (ROS)" is a preferred term to characterize the oxidants involved in such biomolecular modifications. The most frequently generated ROS are the superoxide anion radical, hydrogen peroxide, and hydroxyl radicals, and the main biological targets of ROS are proteins, lipids, and DNA. Oxidative damage is observed as products derived from the oxidative modification of these biomolecules such as proteins and protein-associated carbonyls, advanced glycation end products (AGEs), lipid peroxidation products, lipofuscin, 8-oxo-2'-deoxyguanosine (8-oxodG), etc. ROS are formed continuously in cells during normal cellular metabolism and by exogenous agents such as carcinogenic compounds and ionizing radiation [4]. Thus, such damage is detectable under normal physiological conditions, even in healthy young animals. Although mammalian cells have numerous antioxidant defenses to limit the generation and attack of ROS, such as catalase, superoxide dismutase and glutathione peroxidase, ROS can escape these defense systems and injure biomolecules, suggesting that the efficiency of the antioxidative and repair mechanisms is not complete. The amount of oxidative damage to various biomolecules has been shown to increase during aging in a variety of tissues from different species [3]. Further- more, it has been shown that certain types of pathological lesions arisen with age are associated with increased levels of oxidative damage to cellular biomolecules $[5,6]$. Thus, the rate of ROS formation appears to be a determining factor in the aging process.

\section{Oxidative DNA Damage}

Oxidative damage to DNA is also implicated in mutagenesis and carcinogenesis as well as in aging $[7,8]$. Numerous lesions have been characterized as arising from oxidative damage to DNA. Hydroxyl radicals cause many types of DNA damage including the oxidative modification of bases and sugars, strand breaks, and cross-linking to proteins $[9,10]$. The structures of main modified DNA bases are shown in Fig. 1. The 8-oxodG lesion has been studied most extensively because it is the major oxidative lesion and because it can be detected relatively easily using a variety of assay methods [11]. 8-OxodG has been reported to be induced by the treatment of DNA with Fenton-type reagents [12], carcinogens [13] and $\mathrm{X}$ ray-irradiation [14]. These treatments are known to generate ROS during the reaction. Metal ions, such as iron and copper ions, both of which are<smiles>Cc1cnc(O)nc1O</smiles><smiles>Nc1ccnc(O)n1</smiles><smiles>NC1=NC=NC2NC=NC12</smiles>
adenine

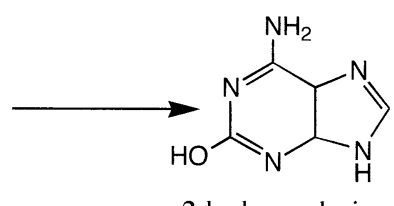<smiles>NC1=NC2NC=NC2C(O)=N1</smiles><smiles>O=c1[nH]cc(CO)c(=O)[nH]1</smiles>

5-hydroxymethyluracil<smiles>Nc1nc(=O)[nH]cc1O</smiles>

5-hydroxycytosine<smiles>NC1=NC=NC2NC(=O)NC12</smiles>

8-oxoadeninel<smiles>CC1(C)CNC(=O)NC1</smiles>

5,6-dihydrothymine 5-hydroxy-5-methylhydantoin<smiles>Nc1nc(=O)[nH]c(O)c1O</smiles><smiles>O=C1NC(=O)C(O)N1</smiles>

5,6-dihydroxycytosine

5-hydroxyhydantoin<smiles>CC1(O)NC(=O)NC1=O</smiles><smiles>Nc1ncnc(N)c1NC=O</smiles>

4,6-diamino-5-formamidopyrimidine<smiles>Nc1nc(N)c(NC=O)c(=O)[nH]1</smiles>

8-oxoguanine 2,6-diamino-4-hydroxy-5-formamidopyrimidine

Fig. 1. Molecular structures of the main modified bases produced from the reaction of DNA with hydroxyl radicals. 


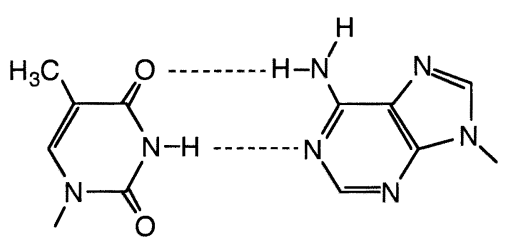

$\mathrm{T}$
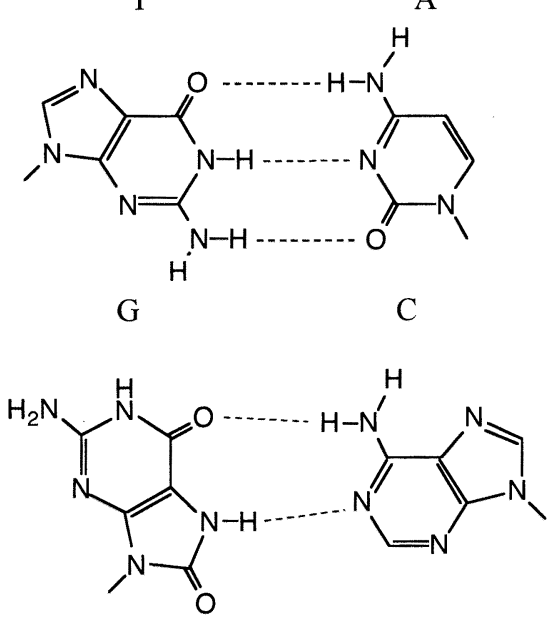

8-oxoG

Fig. 2. Mispairing of $8-\mathrm{oxoG}$ in the syn-conformation (keto form) with adenine.

known to bind to DNA because of its overall negative charge, are believed to produce 8-oxodG through metal-catalyzed oxidation reactions. The $\mathrm{C}$ 8 hydroxyl group of 8-oxodG tautomerizes to the $\mathrm{C}$ 8 keto form (syn-conformation) in neutral aqueous solutions [15]. Since the keto form is more stable than the enol form (8-hydroxyguanine) [16], 8oxodG adopts the syn-conformation. Because 8oxodG pairs preferentially with adenine rather than cytosine, its presence can generate $\mathrm{G} \rightarrow \mathrm{T}$ transversions as shown in Fig. $2[17,18]$, which are likely to be involved in carcinogenesis $[7,8]$. Indeed, 8oxodG has been detected at higher levels in cancer cells $[19,20]$, and, further, the formation of 8oxodG has been demonstrated in target organ DNA in a wide variety of in vivo experimental carcinogenesis models [21,22].

Mitochondrial DNA (mtDNA) is not protected by nucleosomes, being different from nuclear DNA (nDNA), and it lies in close proximity to the free radical producing processes of oxidative phosphorylation. Therefore, mtDNA is thought to be highly prone to oxidative damage. Richter et al. first reported that the levels of 8-oxodG were 16-fold higher in mtDNA than nDNA in rat liver [23]. Subsequently, many investigators have reported significantly higher

levels of 8-oxodG in mtDNA than in nDNA [2426]. However, Higuchi and Linn reported that the levels of 8-oxodG measured in mtDNA isolated by cesium chloride density gradient centrifugation were lower than those reported for nDNA [27]. Anson et al. measured the levels of oxidative damage in mtDNA from rat liver using an Fpg/EndoIII/southern blot assay and concluded that endogenous oxidative damage to mtDNA had been overestimated [28].

\section{Measurement of Oxidative Damage to DNA}

Because the levels of oxidative damage to DNA are low (on the order of fmole range per $\mu \mathrm{g} D N A$ ), it is not easy to detect and quantify these lesions with accuracy. Techniques used to measure oxidative damage to DNA include high-performance liquid chromatography with electrochemical detection (HPLC/ ECD), gas chromatography-mass spectroscopy (GC/ MS), immunochemical techniques, post-labeling assays, and the comet assay for DNA break measurement, not for oxidative damage. The most frequently used technique is HPLC/ECD among these analytical techniques. By the HPLC/ECD following the mild enzymic hydrolysis of DNA, modified nucleosides such as 8-oxodG can be detected in a fmole range [29]. Because of the availability of this technique and of the mutagenic properties of 8-oxodG [17], most studies using HPLC/ECD have concentrated on this compound. On the other hand, GC/ MS in combination with a selective-ion monitoring (SIM) technique can detect a large number of DNA lesions simultaneously. Recently, liquid chromatography/tandem mass spectrometry (LC/MS/MS) [30] and liquid chromatography/mass spectrometry (LC/ MS) [31] have emerged as new techniques for the measurement of modified nucleosides in DNA.

It has become apparent that a significant amount of DNA oxidation can occur during the DNA isolation and sample preparation for assay. The oxidation of intact bases during DNA isolation and/or under subsequent procedures is recognized to depend on analytical techniques used for the measurement of DNA damage. Indeed, it has been shown that DNA is oxidized during isolation, and that precautions must be taken to prevent the oxidation of guanine [32]. The oxidation of DNA has been discussed extensively in recent reviews [33, 34]. Such oxidation has raised important questions about the accuracy of various assays used to measure in vivo levels of DNA 
oxidation. For example, 8-oxodG levels obtained by GC/MS are considerably higher than those obtained using HPLC/EC [35]. Artifacts may occur during the derivatization of DNA acid-hydrolysates at high temperature prior to GC/MS analysis [36]. Guanine is the most prone to oxidation among DNA bases [37], and is oxidized to yield 8-oxoguanine (8oxoG). Several modified bases, such as 5-hydroxycytosine, 8-hydroxyadenine, 5-hydroxymethyluracil, and 5-formyluracil, as well as 8-oxoG, have been reported to be formed during the derivatization procedures for GC/MS [38]. It has been suggested that in the previous works, the derivatization under such improper conditions as the insufficient removal of oxygen might have been made $[35,36,39]$. Because LC/MS/MS and LC/MS do not require sample derivatization for assay, the oxidation of DNA is suppressed [34]. On the other hand, in the case of HPLC/ECD, a significant amount of oxidative damage can be induced during the isolation of DNA, especially in the presence of phenol [40]. Phenol, a reducing agent, is thought to reduce metal ions (e.g., iron ions) present in biological extracts. Reduced metal ions can participate in Haber-Weiss/ Fenton reactions and generate hydroxyl radicals, which can oxidize DNA [41]. Because various tissues contain relatively large amounts of iron ions (2$5 \mathrm{nmol} / \mathrm{mg}$ protein), these reactions could play very important roles in generating oxidative damage during DNA isolation [42]. Nakae et al. reported very low 8-oxodG levels in nDNA isolated from rat liver using sodium iodide ( $\mathrm{NaI}$ ) [43]. In this method, $\mathrm{NaI}$, a chaotropic salt, is used to precipitate proteins from DNA solutions, instead of phenol. With the $\mathrm{NaI}$ method, 8-oxodG levels are very low compared with those obtained by other methods, including the classic phenol method [25, 32]. Recent trials by the European Standards Committee for Oxidative DNA Damage (ESCODD) have shown that the levels of 8-oxoG or 8-oxodG in the same DNA samples measured in various laboratories are inconsistent [4649]. The results strongly suggest that the measurement of 8-oxoG or 8-oxodG may depend on the laboratories and the techniques used.

\section{Repair of DNA Damage}

Oxidative damage to DNA can be repaired by cellular repair systems. The majority of non-bulky modifications, such as damage to DNA bases, are repaired by base-excision repair (BER) [48]. DNA

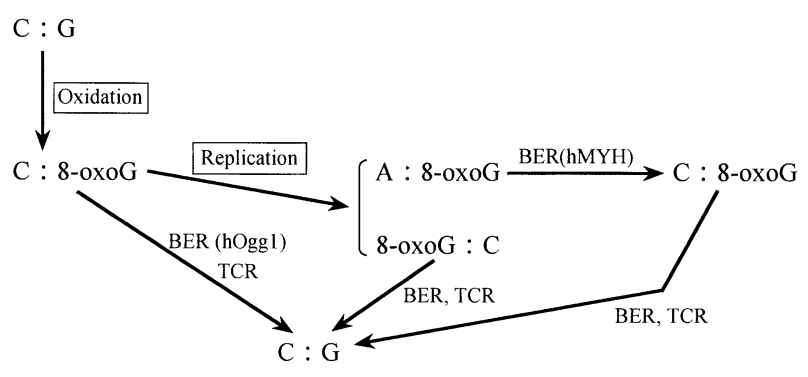

Fig. 3. Possible repair pathway of 8-oxoG in DNA. BER, base excision repair, TCR, transcription-coupled repair.

glycosylases recognize damaged DNA bases and remove the aberrant base by hydrolysis of the $N$-glycosil bond linking the base to the sugar. The resulting abasic site (AP site) is then recognized and cleaved by an AP endonuclease. Finally, a DNA polymerase fills the one-nucleotide gap, and the nick is sealed by DNA ligase. Each modified base is repaired by a specific DNA glycosylase. In the case of 8-oxoG as shown in Fig. 3, in humans, hOgg1 has been identified as a glycosylase with the ability to remove 8-oxoG that is paired opposite cytosine [49]. The mammalian enzyme MYH excises an adenine residue misincorporated opposite an 8-oxoG by mismatch repair [50]. Furthermore, 8-oxoG in DNA has been reported to be removed by transcriptioncoupled repair (TCR) [51]. When DNA containing 8-oxoG is replicated, DNA polymerase $\eta$ can insert a cytosine residue efficiently and accurately across from the lesion [52]. Thus, the 8-oxodG lesion is constantly present at low levels in all cells, although 8-oxoG in DNA can be repaired by some repair enzymes as mentioned above.

Nucleotide excision repair (NER) appears to have a minor function in the repair of oxidative lesions [53]. Through NER of oxidative lesions, 8 -oxoG is likely to result in the excision of a lesion-containing oligomer approximately 25 nucleotides in length. Further, an endonuclease has been reported to cleave the phosphodiester bonds $5^{\prime}$ and $3^{\prime}$ to the 8-oxodG lesion, generating a gap of one nucleotide and releasing 3',5'-8-oxodGDP [54].

\section{Oxidative Damage to DNA and Aging}

Fraga et al. have first observed a significant increase in 8-oxodG levels in nDNA isolated from the liver, kidney, and intestine of male rats 2 to 24 months of age during normal aging, but no increase 
in brain and testes [55]. They suggested that 8oxodG levels increase linearly with age. Sai et al. have also reported that the 8-oxodG levels in the liver and kidney DNA of both male and female rats increase significantly with age, but do not change in the brain, lung, and spleen of male rats, and increase moderately in the brain, lung, and spleen of female rats [56]. Furthermore, the levels of 8 -oxodG in mtDNA isolated from male rat liver increased 2- to 3 -fold with age [5]. Thereafter, a number of research groups have studied age-related changes in the level of 8-oxodG in both nDNA and mtDNA in a variety of animal tissues [24]. However, some groups have reported an inability to detect a significant increase in oxidative damage to DNA in rodent tissues with age $[57,58]$. We tried to clarify whether or not the levels of 8-oxodG in nDNA increase, and whether 8-oxodG levels increase linearly during aging even if antioxidant defense systems comprising of antioxidant enzymes and low molecular weight antioxidants can act in cells. The levels of 8-oxodG in nDNA from male F344 rats 2 to 30 months of age were measured. As shown in Fig. 4, we observed a significant increase in 8-oxodG levels in nDNA in all tissues studied, i.e. liver, brain, kidney, and heart, at 24-30 months of age [59]. The age-related increase in 8-oxodG from 2 to 30 months of age ranged from $65 \%$ for brain, to $100 \%$ for heart, to $140 \%$ for liver and kidney. The age-associated changes in 8-oxodG levels in mammalian tissues exhibited a biphasic increasing pattern. That is, the steady-state levels of 8-oxodG increase slightly during young and middle ages, because the capacity of antioxidant defense systems could fully provide against daily oxidative stress. However, the defense capacity to maintain low 8-oxodG levels may not be retained in old age. Recently, Hamilton et al. conducted a comprehensive study of the effects of age on DNA oxidation and measured the levels of 8-oxodG in DNA isolated from the tissues of young, middle, and old age rodents [60]. They also observed a significant increase in 8-oxodG levels in $\mathrm{nDNA}$ in all tissues, brain, heart, liver, kidney, and muscle of all strains of old rodents studied.

The production rates of superoxide anion and hydrogen peroxide in mitochondria increase during aging in parallel with increases in biomolecular oxidative damage [3]. These relationships suggest that mitochondria play an important role in the aging process. Previous studies have reported an age-related increase in 8-oxodG levels in mtDNA isolated

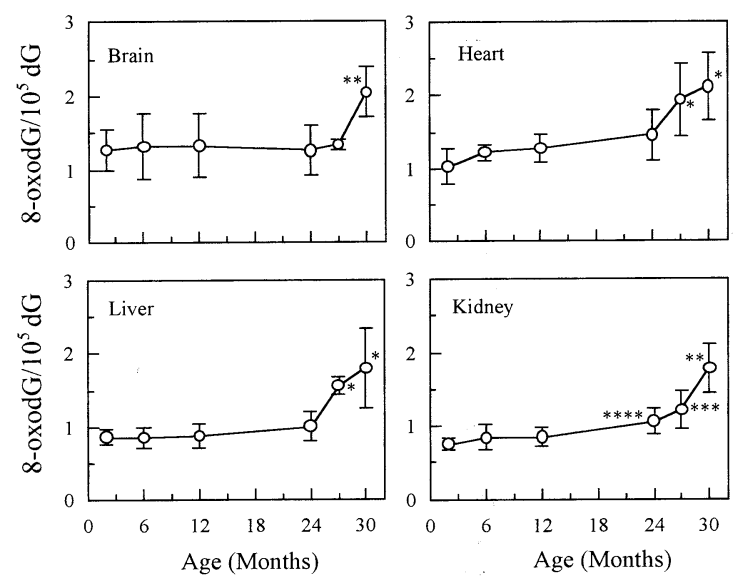

Fig. 4. Changes in 8-oxodG levels of nuclear DNA from tissues of male Fischer 344 rats during aging. *Significantly different from $2,6,12$, and 24 monthold rats at $p<0.01$. ** Significantly different from 2 , $6,12,24$, and 27 month-old rats at $p<0.01$. *** Significantly different from 6 month-old rats at $p<0.05$ and from 2 and 12 month-old rats at $p<0.01$. ${ }^{* * * *}$ Significantly different from 2 and 12 month-old rats at $p<0.05$.

from the liver [5, 24], brain [61], and heart [62] of rodents. However, there is a report that 8 -oxodG in mtDNA has been overestimated [28]. Hamilton et al. [60] used large amounts of liver tissues to increase the yield of mtDNA because the levels of 8-oxodG in DNA are apparently elevated in measurements of samples containing small amounts of mtDNA [63]. They observed that the levels of 8-oxodG in the mtDNA of the livers were 1.3- to 10-fold higher than those in the nDNA, and that the levels of 8oxodG in mtDNA from the livers of old rodents were 1.5- to 2.3-fold higher than those observed in mtDNA from the livers of young rodents. The accumulation of DNA damage and mutations in the genome of old animals is predicted to lead to cellular dysfunction and consequent cell loss.

To understand the mechanism responsible for the age-related increase in 8 -oxodG in tissues in more detail, we examined the time-dependent changes in 8-oxodG levels and the activities of 8-oxodG-releasing enzymes in the livers of young (6 months of age) and old (27 months of age) male F344 rats exposed to $\gamma$-irradiation [64]. Young and old rats were irradiated with $5 \mathrm{~Gy}$ of $\gamma$-rays, and 8-oxodG levels and the activities of 8-oxodG-releasing enzymes were measured at different time intervals after irradiation. The 8-oxodG levels in young and old rats increased immediately and significantly after irradiation as 


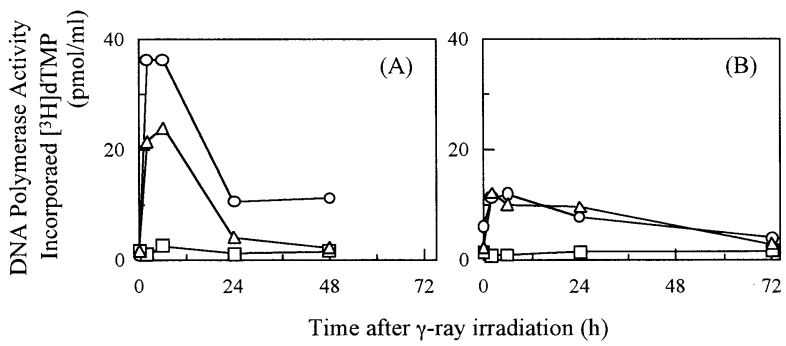

Fig. 5. Changes in DNA polymerase $\alpha(O), \beta(\triangle)$, and $\gamma$ $(\square)$ activities in the livers of male Fischer 344 rats 6 months (A) and 27 months (B) following $\gamma$-ray irradiation. DNA polymerase activities were estimated from the area of the peak from the counts of incorporated $\left[{ }^{3} \mathrm{H}\right] \mathrm{dTMP}$ in each fraction eluted from the phosphocellulose column.

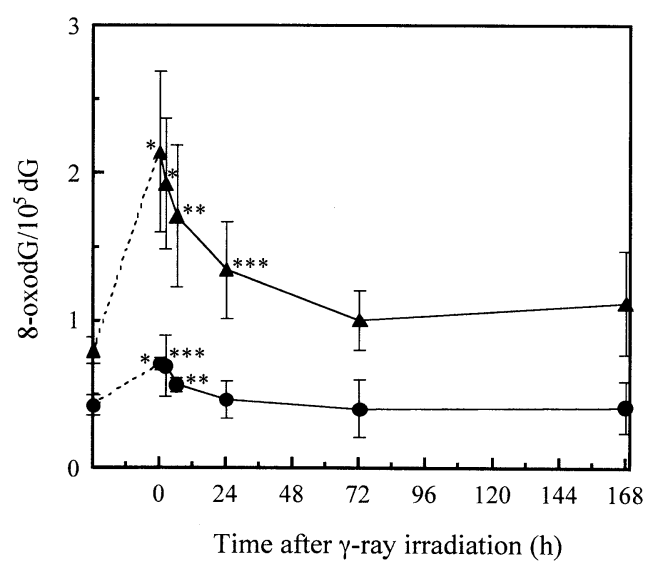

Fig. 6. Changes in the 8-oxodG level of nuclear DNA in Fischer 344 rat liver after $\gamma$-ray irradiation. DNA was extracted from the livers of rats 6 months $(\bullet)$ and 27 months $(\boldsymbol{\Lambda})$ of age exposed to $5 \mathrm{~Gy}$ of $\boldsymbol{\gamma}$ rays. ${ }^{*}$ Significantly different from non-irradiated liver at $p<0.001$. ${ }^{* *}$ Significantly different from non-irradiated liver at $p<0.01$. ${ }^{* *}$ Significantly different from non-irradiated liver at $p<0.05$.

shown in Fig. 5 (1.7- and 2.7-fold, respectively). The level of 8-oxodG in the nDNA of livers of young rats decreased smoothly within a half-life of $6 \mathrm{~h}$ and returned to the basal level by $24 \mathrm{~h}$, while the level in old rats decreased with a half-time of $17 \mathrm{~h}$ and did not return to the basal level even 1 week after irradiation. It has been observed that the $\gamma$-irradiationinduced increase in 8-oxodG levels in $\mathrm{nDNA}$ of livers of young rodents returned rapidly to the basal level $[25,65,66]$. The activity of 8 -oxodG-releasing enzymes in the livers of young rats was found to increase 7 -fold $2 \mathrm{~h}$ after $\gamma$-irradiation and to return to steady-state levels at $24 \mathrm{~h}$ after irradiation, whereas the activity in old rats reached 2 -fold $6 \mathrm{~h}$ after irradiation and returned to the steady-state level at $72 \mathrm{~h}$ after irradiation. Furthermore, DNA polymerase activities were examined in the livers of young and old rats exposed to $\gamma$-irradiation [67]. DNA polymerases $\beta$ and $\gamma$ were induced from 2 to $6 \mathrm{~h}$ after irradiation in both young and old rats. However, the extent of enzyme induction was less in old rats than in young rats (Fig. 6). These results suggest that the ability to repair damaged DNA is lower in aged rats, and that the decline in the repair activity of aged rats is likely to lead to the agedependent accumulation of oxidative damage and DNA mutations in tissues. The tissues of old animals appear to be prone to the generation of oxidative DNA damage when exposed to oxidative stress, e.g., $\gamma$-irradiation. For example, Zahn et al. have reported that DNA strand breaks were induced twice as numerous in tissues from old mice compared with tissues from young mice, when tissues, such as liver or heart, were incubated with nitroquinolin- $N$-oxide in vitro [68]. Guo et al. have found that after UVirradiation, more cyclobutane pyrimidine dimers in nDNA are induced by UV-irradiation in primary cultures of hepatocytes isolated from old rats than from young rats [69].

\section{Effect of Caloric Restriction}

Caloric (dietary) restriction is the only effective manipulation known to extend the life span of rodents and to decrease the incidence of various agerelated diseases $[3,70]$. If the increase in oxidative damage to DNA with age is important in the aging process, the increase should be retarded and/or reduced by dietary restriction. Several reports have indicated that caloric restriction reduces the level of DNA oxidation in rodent tissues [71, 72]. We examined whether or not dietary restriction alters the agerelated accumulation of 8-oxodG in nDNA from tissues of male F344 rats [73]. Under dietary restriction, they were fed 3 days a week (Monday, Wednesday, and Friday) from 4 weeks of age to 33 months of age. The $50 \%$ survival age of the dietary-restricted rats was 35.2 months, while that of ad libitum-fed rats was 28.2 months. There were no differences between the dietary-restricted and ad libitum-fed rats in the 8-oxodG levels of any organ until 24 months of age. However, the levels at 30 months of age were significantly lower in the dietary-restricted rats than 

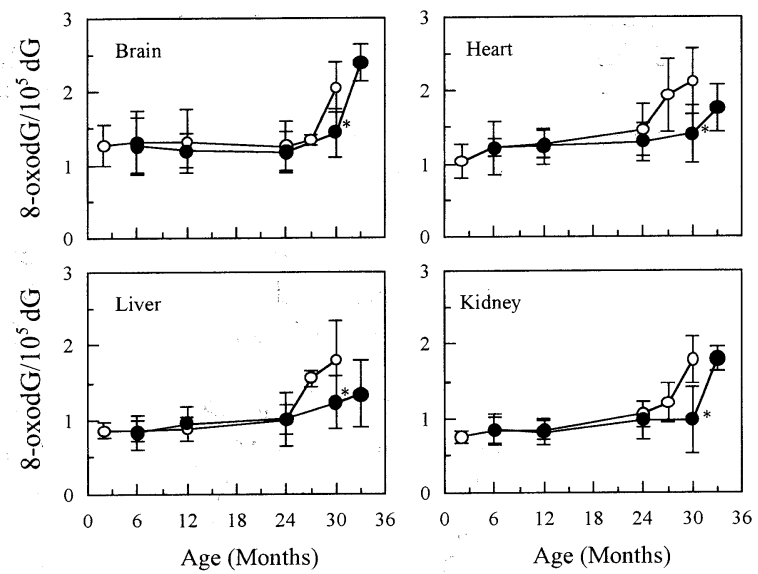

Fig. 7. Comparison of age-related changes in 8-oxodG content of nuclear DNA from tissues of ad libitum-fed and dietary-restricted male Fischer 344 rats. Ad libitum-fed rats (O), dietary-restricted rats

(๑). *Significantly different from ad libitum-fed rats at $p<0.05$.

in ad libitum-fed rats (Fig. 7). These results indicate that dietary restriction can retard the onset of the age-related accumulation of oxidative damage in tissues. Recently, it was observed that the 8-oxodG levels in the nDNA from the brain, heart, and skeletal muscle of old caloric-restricted rats were significantly decreased compared with old ad libitum-fed rats; however, dietary restriction did not decrease the 8oxodG levels in nDNA from rat liver and kidney [60]. Thus, dietary restriction is not likely always to reduce oxidative damage to $\mathrm{nDNA}$ in every tissue and every time. It has also been reported that caloric restriction completely prevents the age-related increase in 8-oxodG levels in liver mtDNA in male F344 rats [60]. Caloric restriction may have a greater effect on the age-related accumulation of oxidative damage in mtDNA than in nDNA.

\section{Conclusion}

Mammalian cells have evolved multiple lines of defense, which include antioxidant enzymes, antioxidants, and DNA repair enzymes, against the accumulation of oxidative damage. The steady state level of modified DNA should be determined by the balance between its formation and removal. The idea that aging may be due to a decrease in antioxidant capacity in old age is not strongly supported, because it has been observed that antioxidant capacity does not change according to a consistent pattern as a function of age; that is, it decreases, increases, or does not change in old animals, depending on the type of antioxidants, tissues, or animal strains. Indeed, Hamilton et al. have found no changes in the activities of $\mathrm{Mn}-\mathrm{SOD}, \mathrm{CuZn-SOD}$, catalase, and glutathione peroxidase between tissues from young and old mice [60]. In addition, antioxidative defenses are not clearly affected by environmental manipulations that increased the longevity of experimental animals, such as caloric restriction in mice. ROS may be produced at specific sites and attack nearby sensitive targets, to which access by antioxidants may be difficult.

The accumulation of oxidative damage to DNA may be a result of deficiencies in DNA damage repair. Indeed, it has been found that the ability to repair damaged DNA is lower in aged rats than in young rats $[64,67]$. Furthermore, it has also been observed that 8-oxodG-incision activity in mouse liver increases with age in mitochondria but not in nuclei [74]. These results support the above-mentioned concept that the decline in repair activity in aged animals leads to the accumulation of oxidative damage in their tissues. Furthermore, the difference between the antioxidant abilities of young and old animals may not be clear under normal conditions. The redundancy of antioxidant activities may decrease in old animals and hence their antioxidants defense may be insufficient to prevent oxidative damage under stressful conditions.

\section{References}

[1] Harman, D.: Aging: a theory based on free radical and radiation chemistry. J. Gerontol., 11, 298-300, 1956.

[2] Warner, H.R.: Superoxide dismutase, aging, and degenerative disease. Free Radic. Biol. Med., 17, 249258, 1994.

[3] Sohal, R. and Weindruch, R.: Oxidative stress, caloric restriction, and aging. Science, 273, 59-63, 1996.

[4] Halliwell, B. and Gutteridge, J.M.C.: Free Radicals in Biology and Medicine, Oxford Science, Oxford, 1999.

[5] Ames, B.N., Shigenaga, M.K., and Hagen, T.M.: Oxidants, antioxidants, and the degenerative diseases of aging. Proc. Natl. Acad. Sci. USA, 90, 7915-7922, 1993.

[6] Rosen, D.R., Siddique, T., Patterson, D., Figlewicz, D.A., Sapp, P., Hentati, A., Donaldson, D., Goto, J., O'Regan, J.P., Deng, H.-Z., Rahmani, Z., Krizus, A., McKenna-Yasek, D., Cayabyab, A., Gaston, S.M., Berger, R., Tanzi, R.E., Halperin, J.J., Herzfeldt, B., Van der Bergh, R., Hung, W.-Y., Bird, T., Deng, G., Mulder, D.W., Smyth, C., Laing, N.G., Soriano, E., Pericak-Vance, M.A., Haines, J., Rouleau, G.A., 
Gusella, J.S., Horvitz, H.R., and Brown Jr, R.H.: Mutations in $\mathrm{Cu} / \mathrm{Zn}$ superoxide dismutase gene are associated with familial amyotropic lateral sclerosis. Nature, 362, 59-62, 1993.

[7] Ames, B.N. and Gold, L.S.: Endogenous mutagens and the causes of aging and cancer. Mutat. Res., 250, 3-16, 1991.

[8] Floyd, R.A.: The role of 8-hydroxyguanine in carcinogenesis. Carcinogenesis, 11, 1447-1450, 1990.

[9] Dizdaroglu, M.: Oxidative damage to DNA in mammalian chromatin. Mutat. Res., 275, 331-342, 1992.

[10] Breen, A.P. and Murphy, J.A.: Reactions of oxyl radicals with DNA. Free Radic. Biol. Med., 18, 1033-1077, 1995.

[11] Helbock, H.J., Beckman, K.B., and Ames, B.N.: 8Hydroxydeoxyguanosine and 8-hydroxyguanine as biomarker of oxidative DNA damage. Methods Enzymol., 300, 156-166, 1999.

[12] Kasai, H. and Nishimura, S.: Hydroxylation of deoxyguanosine at the $\mathrm{C}-8$ position by ascorbic acid and other reducing agents. Nucleic Acids Res., 12, 21372145, 1984.

[13] Fiala, E.S., Conaway, C.C., and Mathis, J.E.: Oxidative DNA and RNA damage in the livers of SpragueDawley rats treated with the hepatocarcinogen 2-nitropropane. Cancer Res., 49, 5518-5522, 1989.

[14] Kasai, H., Tanooka, H., and Nishimura, S.: Formation of 8-hydroxyguanine residues in DNA by X-irradiation. Gann, 75, 1037-1039, 1984.

[15] Culp, S.J., Cho, B.P., Kadlubar, F.F., and Evans, F.E.: Structural and conformational analyses of 8-hydroxy2'-deoxyguanosine. Chem. Res. Toxicol., 2, 416-422, 1989.

[16] Aida, M. and Nishimura, S.: An ab initio molecular orbital study on the characteristics of 8-hydroxyguanine. Mutat. Res., 192, 83-89, 1987.

[17] Moriya, M. and Grollman, A.P.: Mutations in the mut $Y$ gene of Escherichia coli enhance the frequency of targeted G: $\mathrm{C} \rightarrow \mathrm{T}:$ A transversions induced by a single 8-oxoguanine residue in single-stranded DNA. Mol. Gen. Genet., 239, 72-76, 1993.

[18] Cheng, K.C., Cahill, D.S., Kasai, H., Nishimura, S., and Loeb, L.A.: 8-Hydroxyguanine, an abundant form of oxidative DNA damage, cuases $\mathrm{G} \rightarrow \mathrm{T}$ and $\mathrm{A} \rightarrow \mathrm{C}$ substitutions. J. Biol. Chem., 267, 166-172, 1992.

[19] Malins, D.C. and Haimanot, R.: Major alterations in the nucleotide structure of DNA in cancer of the female breast. Cancer Res., 51, 5340-5432, 1991.

[20] Olinski, R., Zastawny, T., Budzbon, J., Skokowski, J., Zegarski, W., and Dizdaroglu, M.: DNA base modifications in chromatin of human cancerous tissues. FEBS Lett., 309, 193-198, 1992.

[21] Chung, F.-L. and Xu, Y.: Increased 8-oxodeoxyguanosine levels in lung DNA of A/J mice and F344 rats treated with the tobacco-specific nitrosamine, 4(methylnitrosamine)-1-(3-pyridyl)-1-butanone. Carcinogenesis, 13, 1269-1272, 1992.
[22] Takabayashi, F., Harada, N., Tahara, S., Kaneko, T., and Hara, Y.: Effect of green tea catechins on the amount of 8-hydroxydeoxyguanosine $(8-\mathrm{OHdG})$ in pancreatic and hepatic DNA after a single administration of $N$-nitroso(2-oxopropyl)amine (BOP). Pancreas, 15, 109-112, 1997.

[23] Richter, C., Park, J.W., and Ames, B.N.: Normal oxidative damage to mitochondrial and nuclear DNA is extensive. Proc. Natl. Acad. Sci. USA, 85, 6465-6467, 1988.

[24] Hudson, E.K., Hogue, B.A., Souza-Pinto, N.C., Croteau, D.L., Anson, R.M., Bohr, V.A., and Hansford, R.G.: Age-associated change in mitochondrial DNA damage. Free Radic. Res., 29, 573-579, 1998.

[25] Hamilton, M.L., Guo, Z.M., Fuller, C.D., Van Remmen, H., Ward, W.F., Austad, S.N., Troyer, D.A., Thompson, I., and Richardson, A.: A reliable assessment of 8-oxo-2-deoxyguanosine levels in nuclear and mitochondrial DNA using the sodium iodide method to isolate DNA. Nucleic Acids Res., 29, 2117-2126, 2001.

[26] Zastaway, T.H., Dabrowska, M., Jaskolski, T., Klimarczyk, M., Kulinski, L., Koszela, A., Szczesniewicz, M., Sliwinska, M., Witkowski, P., and Olinski, R.: Comparison of oxidative base damage in mitochondrial and nuclear DNA. Free Radic. Biol. Med., 24, 722-725, 1998.

[27] Higuchi, Y. and Linn, S.: Purification of all forms of HeLa cell mitochondrial DNA and assessment of damage to it caused by hydrogen peroxide treatment of mitochondria or cell. J. Biol. Chem., 270, 7950-7956, 1995.

[28] Anson, R.M., Hudson, E., and Bohr, V.A.: Mitochondrial endogenous oxidative damage has been overestimated. FASEB J., 14, 355-360, 2000.

[29] Floyd, R.A.: The development of a sensitive analysis for 8-hydroxy-2'-deoxyguanosine. Free Radic. Res. Commun., 8, 139-141, 1990.

[30] Hua, Y., Wainhaus, S.B., Yang, T., Shen, N., Xiong, Y., Xu, X., Zhang, F., Bolton, J.L., and van Breemen, R.B.: Comparison of negative and positive ion electrospray tandem mass spectrometry for the liquid chromatography tandem mass spectrometry analysis of oxidized deoxynucleosides. J. Am. Soc. Mass Spectrom., 12, 80-87, 2001.

[31] Jaruga, P., Rodriguwz, H., and Dizdaroglu, M.: Measurement of 8-hydroxy-2'-deoxyguanosine in DNA by liquid chromatography/mass spectrometry. Free Radic. Biol. Med., 31, 336-344, 2001.

[32] Helbock, H.J., Beckman, K.B., Shigenaga, M.K., Walter, P.B., Woodall, A.A., Yeo, H.C., and Ames, B.N.: DNA oxidation matters: the HPLC-electrochemical detection assay of 8-oxo-deoxyguanosine and 8-oxo-guanine. Proc. Natl. Acad. Sci. USA, 95, 288-293, 1998.

[33] Dizdaroglu, M.: Facts about the artifacts in the measurement of oxidative DNA base damage by gas chro- 
matography-mass spectrometry. Free Radic. Res., 29, 551-563, 1998.

[34] Dizdaroglu, M., Jaruga, P., Birincioglu, M., and Rodriguez, H.: Free radical-induced damage to DNA: mechanisms and measurement. Free Radic. Biol. Med., 32, 1102-1115, 2002.

[35] Ravanat, J.L., Turesky, R.J., Gremaud, E., Trudel, L.J., and Stadler, R.H.: Determination of 8-oxoguanine in DNA by gas chromatography-mass spectrometry and HPLC-electrochemical detection: overestimation of the background level of the oxidized base by the gas chromatography-mass spectrometry assay. Chem. Res. Toxicol., 8, 1039-1045, 1995.

[36] Cadet, J., Douki, T., and Ravanat, J.L.: Artifacts associated with the measurement of oxidized DNA bases. Environ. Health Perspect., 105, 1034-1039, 1997.

[37] Steenken, S. and Jovanovic, S.V.: How easily oxidaizable is DNA? One-electron reduction potentials of adenosine and guanosine radicals in aqueous solution. J. Am. Chem. Soc., 119, 617-618, 1997.

[38] Dizdaroglu, M.: Mechanisms of free radical damage to DNA, in DNA and Free Radicals: Techniques, Mechanisms and Applications, ed. by Aruoma, O.I. and Halliwell, B., St Lucia, OICA International, pp. 3-26, 1998.

[39] Douki, T., Delatour, T., Binachini, F., and Cadet, J.: Observation and prevention of an artifactual formation of oxidized DNA bases and nucleosides in the GCEIMS method. Carcinogenesis, 17, 347-353, 1996.

[40] Claycamp, H.G.: Phenol sensitization of DNA to subsequent oxidative damage in 8-hydroxyguanine assays. Carcinogenesis, 13, 1289-1292, 1992.

[41] Aust, A.E. and Eveleigh, J.F.: Mechanisms of DNA oxidation. Proc. Soc. Exp. Biol. Med., 222, 246-252, 1999.

[42] Sohal, R.S., Wennberg-Kirch, E., Jaiswal, K., Kwong, L.K., and Forster, M.J.: Effects of age and caloric restriction on bleomycin-chelatable and nonheme iron in different tissues of C57BL/6 mice. Free Radic. Biol. Med., 27, 287-293, 1999.

[43] Nakae, D., Mizumoto, Y., Kobayashi, E., Noguchi, O., and Konishi, Y.: Improved genomic/nuclear DNA extraction for 8-hydroxydeoxyguanosine analysis for small amounts of rat liver tissue. Cancer Lett., 97, 233239, 1995.

[44] ESCODD (European Standards Committee on Oxidative DNA damage): Comparison of different methods of measuring 8-oxoguanine as a marker of oxidative DNA damage. Free Radic. Biol. Med., 32, 333-341, 2000.

[45] ESCODD: Inter-laboratory validation of procedures for measuring 8-oxo-7,8-dihydroguanine/8-oxo-7,8dihydro-2'-deoxyguanosine in DNA. Free Radic. Res., 36, 239-245, 2002.

[46] ESCODD: Comparative analysis of baseline 8-oxo-7, 8-dihydroguanine in mammalian cell DNA, by different methods in different laboratories: an approach to consensus. Carcinogenesis, 23, 2129-2133, 2002.

[47] ESCODD: Measurement of DNA oxidation in human cells by chromatographic and enzymic methods. Free Radic. Biol. Med., 34, 1089-1099, 2003.

[48] Wallace, S.S.: Enzymatic processing of radiationinduced free radical damage in DNA. Radiat. Res., 150, S60-S79, 1998.

[49] van der Kemp, P.A., Thomas, D., Barbey, R., de Oliveira, R., and Boiteux, S.: Cloning and expression in Escherichia coli of the OGG1 gene of Saccharomyces cerevisiae, which codes for a DNA glycosylase that excises 7,8-dihydro-8-oxoguanine and 2,6-diamino-4hydroxy-5-N-methylformamidopyrimidine. Proc. Natl. Acad. Sci. USA, 93, 5197-5202, 1996.

[50] McGoldrick, J.P., Yeh, Y.-C., Solomon, M., Essigmann, J.M., and Lu, A.-L.: Characterization of a mammalian homolog of the Escherichia coli MutY mismatch repair protein. Mol. Cell. Biol., 15, 989-996, 1995.

[51] Le Page, F., Kwoh, E.E., Avrutskaya, A., Gentil, A., Leadon, S.A., Sarasin, A., and Cooper, P.K.: Transcription-coupled repair of 8-oxoguanine: requirement for XPG, TFIIH, and CSB and implications for Cockayne syndrome. Cell, 101, 159-171, 2000.

[52] Haracska, L., Yu, S.L., Johnson, R.E., Prakash, L., and Prakash, S.: Efficient and accurate replication in the presence of 7,8-dihydro-8-oxoguanine by DNA polymerase $\eta$. Nat. Genet., 25, 458-461, 2000.

[53] Reardon, J.T., Bessho, T., Kung, H.C., Bolton, P.H., and Sancar, A.: In vitro repair of oxidative DNA damage by human nucleotide excision repair system: possible explanation for neurodegeneration in Xeroderma pigmentosum patients. Proc. Natl. Acad. Sci. USA, 294, 9463-9468, 1997.

[54] Bessho, T., Roy, R., Yamamoto, K., Kasai, H., Nishimura, S., Tano, K., and Mitra, S.: Repair of 8-hydroxyguanine in DNA by mammalian $N$-methyl purineDNA glycosylase. Proc. Natl. Acad. Sci. USA, 90, 89018904, 1993.

[55] Fraga, C.G., Shigenaga, M.K., Park, J.W., Degan, P., and Ames, B.N.: Oxidative damage to DNA during aging: 8-Hydroxy-2'-deoxyguanosine in rat organ DNA and urine. Proc. Natl. Acad. Sci. USA, 87, 45334537, 1990.

[56] Sai, K., Takagi, A., Umemura, T., Hasegawa, R., and Kurokawa, Y.: Changes of 8-hydroxydeoxyguanosine levels in rat organ DNA during the aging process. $J$. Environ. Pathol. Toxicol. Oncol., 11, 139-143, 1992.

[57] Yamamoto, F., Kasai, H., Togashi, Y., Takeichi, N., Hori, T., and Nishimura, S.: Elevated level of 8hydroxydeoxyguanosine in DNA of liver, kidneys, and brain of Long-Evans Cinnamon rats. Jpn. J. Cancer Res., 84, 508-511, 1993.

[58] Hirano, T., Yamaguchi, R., Asami, S., Iwamoto, N., and Kasai, H.: 8-Hydroxyguanine levels in nuclear DNA and its repair activity in rat organs associated with age. J. Gerontol. A Biol. Sci. Med. Sci., 51: B303- 
B307, 1996.

[59] Kaneko, T., Tahara, S., and Matsuo, M.: Non-linear accumulation of 8-hydroxy-2'-deoxyguanosine, a marker of oxidized DNA damage, during aging. Mutat. Res., 316, 277-285, 1996.

[60] Hamilton, M.L., Van Remmen, H., Drake, J.A., Yang, H., Guo, Z.M., Kewitt, K., Walter, C.A., and Richardson, A.: Does oxidative damage to DNA increase with age ? Proc. Natl. Acad. Sci. USA, 98, 10469-10474, 2001.

[61] Mecocci, P., MacGarvey, U., Kaufman, A.E., Koontz, D., Shoffner, J.M., Wallace, D.C., and Beal, M.F.: Oxidative damage to mitochondrial DNA shows marked age-dependent increases in human brain. Ann. Neurol., 34, 609-616, 1993.

[62] Muscari, C., Giaccari, A., Stefanelli, C., Viticchi, C., Giordano, E., Guarnieri, C., and Caldarera, C.M.: Presence of a DNA-4236 bp deletion and 8-hydroxydeoxyguanosine in mouse cardiac mitochondrial DNA during aging. Aging, 8, 429-433, 1996.

[63] Beckman, K.B. and Ames, B.N.: Detection and quantification of oxidative adducts of mitochondrial DNA. Methods Enzymol., 264, 442-453, 1996.

[64] Kaneko, T., Tahara, S., Tanno, M., and Taguchi, T.: Effect of age on the induction of 8-oxo-2'-deoxyguanosine-releasing enzyme in rat liver by $\gamma$-ray irradiation. Arch. Gerontol. Geriatr., 36, 23-35, 2003.

[65] Kasai, H., Crain, P.F., Kuchino, Y., Nishimura, S., Ootsuyana, A., and Tanooka, H.: Formation of 8hydroxyguanine moiety in cellular DNA by agents producing oxygen radicals and evidence for its repair. Carcinogenesis, 7, 1849-1851, 1986.

[66] Zastawny, T.H., Czerwinska, B., Drzewiecka, B., and Olinski, R.: Radiation induced oxidative DNA base damage and its repair in liver chromatin DNA of rats upon whole body $\gamma$-irradiation. Acta Biochim. Pol., 43,
$579-582,1996$

[67] Kaneko, T., Tahara, S., Tanno, M., and Taguchi, T.: Age-related changes in the induction of DNA polymerases in rat liver by $\gamma$-ray irradiation. Mech. Ageing Dev., 123, 1521-1528, 2002.

[68] Zahn, R.K., Jaud, S., Schroder, H.C., and ZahnDaimler, G.: DNA status in brain and heart as prominent co-determinant for life span ? Assessing the different degrees of DNA damage, damage susceptibility, and repair capability in different organs of young and old mice. Mech. Ageing Dev., 89, 79-94, 1996.

[69] Guo, Z., Heydari, A., and Richardson, A.: Nucleotide excision repair of actively transcribed versus nontranscribed DNA in rat hepatocytes: effect of age and dietary restriction. Exp. Cell Res., 245, 228-238, 1998.

[70] Weindruch, R. and Walford, R.L.: The Retardation of Aging and Disease by Dietary Restriction, Thomas, Springfield, IL, 1988.

[71] Chung, M.H., Kasai, H., Nishimura, S., and Yu, B.P.: Protection of DNA damage by dietary restriction. Free Radic. Biol. Med., 12, 523-525, 1992.

[72] Sohal, R.S., Agarwal, S., Candas, M., Forster, M.J., and Lal, H.: Effect of age and caloric restriction on DNA oxidative damage in different tissue of C57BL/ 6 mice. Mech. Ageing Dev., 76, 215-224, 1994.

[73] Kaneko, T., Tahara, S., and Matsuo, M.: Retarding effect of dietary restriction on the accumulation of 8hydroxy-2'-deoxyguanosine in organs of Fischer 344 rats during aging. Free Radic. Biol. Med., 23, 76-81, 1997.

[74] de Souza-Pinto, N.C., Hogue, B.A., and Bohr, V.A.: DNA repair and aging in mouse liver: 8-oxodG glycosylase activity increase in mitochondrial but not in nuclear extracts. Free Radic. Biol. Med., 30, 916-923, 2001. 